\title{
Domestic Violence, Marital Control, and Family Planning, Maternal, and Birth Outcomes in Timor-Leste
}

Rebecca Meiksin, MPH; Research Fellow, London School of Hygiene and Tropical Medicine (rebecca.meiksin@lshtm.ac.uk)

Dominique Meekers, PhD; Tulane University School of Public Health and Tropical Medicine (dmeekers@tulane.edu)

Susan Thompson, MPH; Health Alliance International at the University of Washington (thompssu@uw.edu)

Amy Hagopian, PhD; Health Alliance International at the University of Washington (hagopian@uw.edu)

Mary Anne Mercer, DrPH; Health Alliance International at the University of Washington (mamercer@uw.edu) 


\section{Abstract}

\section{Title}

Domestic Violence, Marital Control, and Family Planning, Maternal, and Birth Outcomes in Timor-Leste

\section{Objectives}

Patriarchal traditions and a history of armed conflict in Timor-Leste provide a context that facilitates violence against women. More than a third of ever-married Timorese women report physical and/or sexual domestic violence (DV) perpetrated by their most recent partner. DV violates women's rights and may threaten their reproductive health. Marital control may also limit women's reproductive control and healthcare access. Our study investigated relationships between DV and marital control and subsequent family planning, maternal healthcare, and birth outcomes in Timor-Leste.

\section{Methods}

Using logistic regression, we examined 2009-10 Demographic and Health Survey data from a nationally representative sample of 2,951 women in Timor-Leste. We controlled for age, education, and wealth. We limited our analyses of pregnancy- and birth-related outcomes to those from the six months preceding the survey.

\section{Results}

Rural women with controlling husbands were less likely than other rural women to have an unmet need for family planning (AdjOR=0.6; 95\%CI 0.4-0.9). Rural women who experienced DV were more likely than other rural women to have an unplanned pregnancy (AdjOR=2.6; 95\%CI 1.4-4.8), fewer than four antenatal visits (AdjOR=2.3; 95\%CI 1.1-4.9), or a baby born smaller than average (AdjOR=3.1; 95\%CI 1.4-6.7). DV and marital control were not associated with the tested outcomes among urban women.

\section{Conclusions}

Given high rates of DV internationally, our findings have important implications.

Preventing DV may benefit both women and future generations. Furthermore, rural women who experience DV may benefit from targeted interventions that mediate associated risks of negative family planning, maternal healthcare, and birth outcomes.

\section{Keywords}

1. domestic violence

2. marital control

3. birth outcomes

4. family planning

5. maternal care 


\section{Domestic Violence, Marital Control, and Family Planning, Maternal, and Birth Outcomes in Timor-Leste}

\section{Introduction}

Gender inequality is a major driver of violence against women (VAW), a worldwide problem of "epidemic proportions."(1,p.5) A 2013 World Health Organization (WHO) report estimates that globally, 35\% of women experience physical and/or sexual violence at the hand of an intimate partner (domestic violence, or DV) or sexual violence perpetrated by a non-partner.(1) Lifetime prevalence of DV is highest in South-East Asia, where nearly $38 \%$ of ever-partnered women have been abused by a partner.(1)

In Timor-Leste, a South-East Asian nation of 1.2 million people, gender inequality and a history of violent occupation contribute to high rates of VAW and DV. Though the Constitution promotes gender equality,(2) the primarily patriarchal Timorese society(2-6) is organized by strict gender roles and norms that establish male dominance and a lower status for women.(2,3,5-7) The tradition of bridewealth may contribute to a sense of men's ownership over their wives, $(2,3)$ and in some areas a belief persists that husbands should beat their wives to educate or punish them. $(3,8)$

Following 400 years of colonial rule by Portugal, Timorese society endured a 24-year occupation by Indonesia. The occupation was characterized by widespread violence and human rights abuses, including "state-sanctioned sexual abuse" wielded as a political weapon against women who were suspected, or whose partners were suspected, of 
association with pro-independence forces.(4,p.4) Militarization continued afterwards with the arrival of United Nations peacekeeping forces,(9) which was followed by internal violence in 2006-2007. Trauma and recurrent violence have been harmful to the Timorese population. One study found that the internal violence in 2006-2007 was associated with a seven-fold increase in post-traumatic stress disorder and an almost three-fold increase in severe distress(10). In another analysis, prevalence of explosive anger was 38\% among a sample of 1,544 adults in Timor-Leste and trauma exposure was identified as a predictor of explosive anger.(11) Many agree that the history of violence contributes to ongoing violence in Timor-Leste(9), including VAW and DV; $(4,5)$ in fact, some men who survived detention and torture admitted to having "fallen into a pattern of violent behavior."(12,p.169)

In "East Timorese Women Challenge Domestic Violence," Hall discusses the evolution of the Timor-Leste women's movement, grown out of women's involvement in the fight for independence from Indonesia.(13) With international support, local NGOs have “collectively challenge[d] traditional norms that facilitate domestic violence."(13,p.315) The women's movement has made substantial victories, including successfully lobbying the United Nations Transitional Administration in East Timor to draft a policy paper on domestic violence and to solicit contributions from rural women for the draft.(13) However, "true transformation of gendered social, political and economic relations" in Timor-Leste has not yet come to fruition.(13,p.323) 
Reported rates of DV in Timor-Leste vary widely across the nation's 13 districts, and they are higher among urban than rural women.(14) Using a variety of methods, researchers have explored causes of gender inequity and gender-based violence in Timor-Leste's districts of Covalima, Oecusse, and Bobonaro.(3,5,8) However, we are not aware of comparative studies that account for regional differences in reported violence. On average, more than one in three ever-married women say they have experienced DV from their current or most recent partner, and one in five of those women sustained injuries. ${ }^{\mathrm{i}, i i}(14)$

DV can be associated with mental health issues including anxiety,(15) depression, $(1,15,16)$ alcohol and drug dependence, suicide attempts, and post-traumatic stress disorder.(16) Many studies have also documented relationships between DV and women's reproductive health, maternal healthcare, and birth outcomes, including both unplanned pregnancy and abortion. $(1,15,17)$

DV before or during pregnancy can be associated with increased risk for hypertension, edema, vaginal bleeding, vomiting and dehydration, and urinary tract infections,(18) and physical violence from a partner may be associated with prenatal hospitalization and a deficit in gestational weight gain.(15) Furthermore, abusive partners may prevent women from getting proper prenatal or postnatal care.(16) It is unsurprising, then, that DV can also be associated with negative pregnancy outcomes like spontaneous abortion and fetal loss.(19) A global systematic review found that women who experience DV are $16 \%$ more likely to have a low birthweight baby and $41 \%$ more likely to have a preterm birth,(1) both of which are associated with cognitive deficits, attention, behavior, and psychological difficulties, and permanent growth restriction.(20) 
Studies have produced conflicting results on associations between DV and partner emotional violence and contraception use, variably showing a positive relationship,(19) an inverse relationship,(21) or no significant relationship at all.(22)

Garcia-Morena, et al., present a conceptual model showing hypothesized pathways through which DV can lead to maternal and perinatal problems.(1,p.8) The model maps how DV can lead to psychological stress, fear, and a lack of control that result in women's limited reproductive control, barriers to healthcare access, and ultimately negative family planning, maternal healthcare, and birth outcomes.

The same study highlights the "less documented, but emerging pathway" through which a partner's controlling behaviors - often co-occurring with physical or sexual violence - may limit women's sexual and reproductive control, healthcare access, and medication adherence.(1,p.7) This is salient to Timor-Leste, where only 53\% of ever-married women say their partner displays no controlling behaviors. ${ }^{i i i}(14)$ A 2013 report suggests a higher number of controlling behaviors is also associated with an increased risk of violence in Timor-Leste.(23)

Given the high prevalence of maternal, infant, and under-five mortality and low rates of healthcare center deliveries and skilled birth attendance, a 2013 review of health data in Timor-Leste proposes maternal health as one of four priority research areas for the nation.(24) 
Timor-Leste's high prevalence of DV, coupled with evidence of DV's association with negative maternal and birth outcomes, suggests DV could be an important target for intervention. Emerging evidence also indicates that the high prevalence of marital control in Timor-Leste could undermine family planning. However, to our knowledge only one report has investigated the relationship between violence against women (combining partner- and non-partner violence) and maternal and birth outcomes in Timor-Leste, and none has focused on DV specifically or examined the relationship between marital control and family planning in the Timorese context.(23) Our paper assesses the relationship between DV and family planning, maternal healthcare, and birth outcomes among women in Timor-Leste, and it examines whether women with a controlling partner were more likely to experience unplanned pregnancy and an unmet need for family planning.

\section{Methods}

\section{Sample}

Data for this study come from the Timor-Leste Demographic and Health Survey 2009-10 (TLDHS) conducted by the National Statistics Directorate of the Ministry of Finance, with technical assistance from ICF Macro (now known as ICF International). This cross-sectional survey collected data on many health topics, including fertility and family planning behavior, utilization of maternal health services, and domestic violence and marital control. Designed to yield representative results for most indicators at the national level, for urban and rural areas, and for each of the 13 districts, the TLDHS used a two-stage stratified sample. For detailed information on sampling design and survey methods, see National 
Statistics Directorate (NSD) [Timor-Leste], et al.(14) We used the Complex Samples add-on module of IBM SPSS Statistics Version 21 to correct for the stratified nature of the sample.

The Institutional Review Board (IRB) of ICF Macro, in compliance with the United States Department of Health and Human Services' regulations for the protection of human research subjects, approved the MEASURE Demographic and Health Surveys Project Phase III, which includes the TLDHS. TLDHS data are publicly available and not identifiable; therefore, the University of Washington Human Subject Division's policy excludes this secondary analysis from review by the university's IRB.

After informed consent, trained fieldworkers administered the TLDHS Women's Questionnaire as face-to-face interviews. Between August 2009 and February 2010 they interviewed 13,137 women ages 15-49. They also administered a DV module to one randomly selected woman in one-third of households selected for the TLDHS. The module was administered only if privacy could be obtained, and respondents were read an additional statement at the beginning of the section informing them the questions could be sensitive and reaffirming the confidentiality of their responses. A total of 2,951 women participated in the DV module.

We analyzed data for ever-married women who participated in the DV module, who were asked about their experience of DV and controlling behaviors from their current/most recent partner. We used different sub-samples of these respondents depending on the analysis, as shown in Table 1. The data do not provide any information on when the 
measured DV or marital control events occurred. Hence, it would be possible for the DV or marital control event to have occurred after the maternal healthcare, birth, and unplanned pregnancy outcomes..$^{\text {iv }}$ To reduce the risk of this, we limited the samples for unplanned pregnancy and maternal healthcare and birth outcomes to women who had a very recent outcome. Specifically, we limited our unplanned pregnancy analyses to women who were pregnant at the time of the survey or gave birth in the six months prior to the survey, and we limited the maternal healthcare and birth outcomes to women who gave birth in the six months prior to the survey. Unweighted sizes of each sample are given in both Tables 1 and 2.

Measures

\section{Exposures}

For women who were currently married or living with a man as if married, questions about DV and controlling behavior refered to their current partner. For formerly married women and women who lived with a man as if married in the past only, these questions refered to their last partner.

Domestic violence. Ever-married respondents were asked if their current/last partner ever did any of the following: (a) push you, shake you, or throw something at you? (b) slap you? (c) twist your arm or pull your hair? (d) punch you with his fist or something that could hurt you? (e) kick you, drag you or beat you up? (f) try to choke you or burn you on purpose? (g) threaten or attack you with a knife, gun, or any other weapon? (h) physically force you to 
have sexual intercourse with him even when you did not want to? (i) force you to perform any sexual acts you did not want to?

Women who answered "yes" to any of these questions were considered to have experienced DV. Women who were married only once and whose sexual initiation was forced by their current/last partner were also considered to have experienced DV.

Marital control. Ever-married women were asked if any of the following apply/applied to their relationship with their current/last partner: (a) He (is/was) jealous or angry if you (talk/talked) to other men? (b) He frequently (accuses/accused) you of being unfaithful? (c) He (does/did) not permit you to meet your female friends? (d) He (tries/tried) to limit your contact with your family? (e) He (insists/insisted) on knowing where you (are/were) at all times? (f) He (does/did) not trust you with any money?

The 2009-2010 TLDHS report notes that "the accumulation of such [marital control] behaviors is more significant than the results for any single behavior,"(14,p.236) and a secondary analysis of TLDHS data supports this.(23) Accordingly, the TLDHS report highlights the proportion of women who said that their partner displays/displayed three or more of the specified behaviors. To be consistent with the TLDHS report, we considered women who answered "yes" to three or more of the questions on marital control to have a controlling partner.

\section{Family Planning Outcomes}

We tested associations between DV and marital control and two family planning outcomes: 
1. Unmet need for family planning, including for both spacing and limiting childbearing: In brief, this variable indicates that the respondent was not seeking pregnancy at the time of the survey but was not using contraception. For detailed information on definitions of unmet need, see National Statistics Directorate (NSD) [Timor-Leste], et al.(14,p.95)

2. Unplanned current pregnancy or last birth ("unplanned pregnancy"): The respondent reported that when she became pregnant with her current pregnancy (if pregnant) or with the baby she most recently delivered (if not currently pregnant), she had wanted to postpone pregnancy or wanted no more children. All other women who had a child in the six months preceding the survey or who were pregnant at the time of the survey were categorized as not having had an unplanned pregnancy. Because this measure refers only to women who were either pregnant at the time of the survey or had a child in the prior six months, it excludes women who had a pregnancy in this time period that ended in induced abortion, spontaneous abortion, or stillbirth.

\section{Maternal Healthcare and Birth Outcomes}

WHO recommends that all pregnant women attend a minimum of four antenatal care (ANC) visits.(25) Accordingly, we tested associations between DV and the following outcomes for respondents' most recent birth in the past six months: (a) no ANC from a skilled ANC provider; (b) fewer than four ANC visits; (c) did not use a skilled birth attendant; ${ }^{\text {vi }}(\mathrm{d})$ delivered outside of a healthcare facility; (e) mother reports baby was small 
or very small at birth; ;ii (f) no maternal postnatal check (PNC) within one day after birth; and (g) no maternal PNC within six weeks after birth.

\section{Analysis}

We first conducted unadjusted and adjusted binary logistic regression for overall samples, then for samples stratified by urban/rural residence. We calculated odds ratios and conducted tests of independence. All analyses are weighted using the statistical weight provided in the TLDHS dataset for the DV module.

To control for potential confounders, adjusted models included age as a covariate and education level and wealth tertile as factors. The education level variable indicates the highest level of education attended: no education, primary, or secondary and higher. We created the wealth tertiles variable by recoding the wealth index factor score for all women in the TLDHS sample $(\mathrm{N}=13,137)$.

We conducted additional analyses to determine whether to adjust for DV in the marital control models and whether to adjust for marital control in the DV models (not shown). We found that DV was not significantly associated with both the exposure and outcome tested in any of the marital control models; it was therefore not a confounder. Similarly, we found that marital control was not significantly associated with both the exposure and outcome tested in any of the DV models. viii Since DV and marital control were not confounders, we did not control for them in the logistic regression models. 


\section{Results}

\section{Background Characteristics}

Table 2 shows the background characteristics of women from the three samples used in our analyses. Unweighted sample sizes varied based on the characteristics relevant to each analysis, ranging from 294 to 2,162 women.

Average age across the samples ranged from 29 to 33, and most women (74\% to $77 \%$, depending on the sample) lived in rural areas. Depending on the sample, $95 \%$ to $99 \%$ of women were married at the time of the survey, between $37 \%$ and $43 \%$ were in the poorest wealth tertile, and between $33 \%$ and $37 \%$ had no education.

\section{Predictor Variables}

We used two variables (DV and marital control) to predict nine binary outcome variables. Depending on the sample, $35 \%$ to $41 \%$ of women reported experiencing DV and $11 \%$ to $13 \%$ reported marital control.

\section{Logistic regression}

We used Pearson Chi-square tests to test the association between DV and each outcome. Similarly, we used Pearson Chi-square tests to test the association between marital control and unmet need for family planning and unplanned pregnancy.

\section{Family Planning Outcomes}

Table 3 shows unadjusted and adjusted odds ratios from logistic regression models that tested relationships between DV/marital control and family planning outcomes. In the 
sample used to investigate unmet need for family planning, $29 \%$ of respondents had an unmet need. In the sample used to investigate unplanned pregnancy, which was limited to women who either gave birth in the 6 months prior to the survey or were pregnant at the time of the survey, $17 \%$ of respondents had an unplanned pregnancy in the past 6 months.

\section{Domestic Violence}

DV was not significantly associated with unmet need for family planning in our analysis.

We found significant associations between DV and unplanned pregnancy. Overall, women who reported experiencing DV were more than twice as likely as other women to have had an unplanned pregnancy in the past six months (AdjOR=2.2; $95 \% \mathrm{CI}=1.3,3.7$ ). After analysis by place of residence, the association held for rural women (AdjOR=2.6; 95\%CI=1.4, 4.8) but not urban women.

\section{Marital Control}

We found no significant association between marital control and unmet need for family planning among urban women. Perhaps surprisingly, rural women reporting marital control were significantly less likely than other rural women to have an unmet need for family planning (AdjOR=0.6; 95\%CI=0.4, 0.9).

Among women overall, those reporting marital control were more than twice as likely as other women to have had an unplanned pregnancy in the past six months (AdjOR=2.2; $95 \% \mathrm{CI}=1.0,4.5)$, but the association was no longer significant when we examined urban and rural women separately. 


\section{Maternal Healthcare and Birth Outcomes}

Table 4 shows unadjusted and adjusted odds ratios from logistic regression models that tested relationships between DV and maternal healthcare and birth outcomes. In our sample, $48 \%$ of respondents had fewer than four ANC visits. Overall, the odds of having fewer than four ANC visits were almost three times greater for women who reported experiencing DV than for those who did not (AdjOR=2.7, 95\%CI=1.4, 5.1). By urban/rural status, only rural women were more likely to have fewer than four ANC visits if they had experienced DV (rural AdjOR=2.3, 95\%CI=1.1, 4.9); we found no significant association among urban women.

In our sample, $20 \%$ of mothers reported that their most recent baby was small or very small at birth. Rural women who experienced DV were more than three times as likely as other rural women to report having a baby born small or very small (AdjOR=3.1; 95\%CI=1.4, 6.7). Among urban women, DV was not significantly associated with reported birth size.

In our sample, $16 \%$ of women had no ANC from a skilled ANC provider, $66 \%$ did not use a skilled birth attendant, $72 \%$ delivered outside of a health facility, $76 \%$ had no PNC within one day after birth, and 64\% had no PNC within six weeks after birth. As shown in Table 4, we found no significant association between DV and any of these outcomes. ${ }^{\text {ix }}$ 


\section{Discussion}

Rooted in gender inequality, DV undermines women's human rights and their physical and mental health. In Timor-Leste, we found DV is also associated with significantly higher odds of negative family planning, maternal healthcare, and birth outcomes.

By restricting our analyses of pregnancy- and birth-related outcomes to those from the six months before the survey, we increased the likelihood that the exposure (marital control or DV) preceded the outcomes. This sequence of events is even more likely given that worldwide prevalence of DV is already high (28\%) among women ages 15-19, suggesting that DV tends to start early in relationships.(1) Researchers suggest that for some reproductive health and birth outcomes, the consistency $(17,19)$ and strength of the associations with DV and the "plausible mechanisms of causality" make causation likely.(17,p.8) Our results are consistent with those findings.

We found that in rural Timor-Leste, DV was associated with unplanned pregnancy, attending fewer than four ANC visits, and more than triple the likelihood of giving birth to smaller than average babies. The last finding is especially concerning, as low birthweight is a leading cause of newborn morbidity and mortality.(20)

Urban women seemed not to experience the same negative outcomes associated with DV. It may be that urban women can more easily access healthcare without their partner's knowledge. Alternatively, the lack of association between DV and negative reproductive 
health outcomes in urban settings may be attributable to small sample sizes. Future studies should re-test this relationship using larger urban samples.

Our findings on marital control and family planning mirror the conflicting results found in the literature. $(19,21,22)$ Marital control was associated with twice the odds of unplanned pregnancy overall. Perhaps because of small sample sizes, the relationship was no longer significant when we stratified the sample by urban/rural residence. However, rural women with a controlling partner were less likely than other rural women to have an unmet need for family planning. Future qualitative research should investigate the interplay between marital control and couples' fertility preferences and contraceptive decision-making.

The TLDHS reported major differences in DV and marital control by district. In Manatuto, $11 \%$ of ever-married women reported DV from their current/last partner, compared to 78\% in Manufahi. Rates of marital control ranged from 5\% in Oecussi to 30\% in Dili. The TLDHS also asked women and men if a husband was justified in beating his wife for five different reasons. Only 2\% of men in Manatuto agreed with at least one of the reasons, compared to $95 \%$ of men in Covalima.(14) Our sample size was too small to investigate regional differences. Future research should investigate whether DV and marital control operate differently by district, given the broad variations in prevalence and attitudes. Findings would allow investigation of factors associated with the variation, perhaps leading to meaningful interventions. 


\section{Limitations}

Our study has limitations. First, the DV module was asked of a relatively small subset of women who participated in the TLDHS. Limited sample sizes, especially for pregnancy- and birth-related outcomes and urban samples, limited our power to detect significant associations and prevented us from controlling for additional variables that may be important. Furthermore, limited sample sizes required that we control for age as a continuous variable rather than by age group, potentially obscuring age group differences that are not linear.

As with all cross-sectional studies, we cannot be certain that the exposures preceded the outcomes tested. Additionally, survey respondents may not recall past events with perfect accuracy. Limiting the time-frame of pregnancies and births to the past six months mediates, though cannot fully address, both of these limitations. The use of cross-sectional data also means that we cannot infer that the predictor variables caused the outcomes measured in this study.

Finally, despite the efforts of the TLDHS to create a safe environment, respondents may underreport DV and marital control due to discomfort sharing their experiences.

\section{Implications}

DV is closely linked with maternal and pregnancy outcomes globally, and evidence suggests that for at least some of these outcomes the relationship is likely causal.(17,19) A 2010 study of DV and partner emotional violence during pregnancy across 19 countries 
concluded "global initiatives to reduce maternal mortality and morbidity and improve maternal health" should increase attention to VAW, especially during pregnancy, given its high prevalence and "potential impact on maternal and newborn health."(26,p.168) Still, primary prevention of VAW is typically neglected(27) and few studies have been designed or appropriately powered to detect the effectiveness of potential interventions.(18)

Our findings suggest that in the short-term, targeted interventions addressing family planning, maternal healthcare, and birth outcome vulnerabilities for Timorese women who have experienced DV or marital control would be a good use of public health resources, due to their elevated risk. Rural women appear most vulnerable, though research with larger urban samples could determine risks for urban women as well. Interventions targeting birth size should be prioritized, given the long-term consequences of low birthweight that span a broad range of cognitive, psychological, and physical problems.(20)

Experts agree that addressing social and cultural norms that elevate men's status over women's is key in preventing DV,(1,27) and a 2010 WHO report on the prevention of DV, partner emotional violence, and non-partner sexual violence found emerging evidence in support of efforts to change gender norms.(27) Qualitative research confirms that in the Timorese context, DV is rooted in gender norms and in social acceptability of VAW.(4,8) In the longer term, the international community should support interventions targeting root causes of DV and marital control. These efforts are key to protecting women's rights, and they may also improve both maternal and newborn health in Timor-Leste. 


\section{References}

1. Garcia-Morena C, Pallitto CC, Devries K, Stockl H, Watts C, Abrahams N. Global and regional estimates of violence against women: prevalence and health effects of intimate partner violence and non-partner violence. Geneva: World Health Organization; 2013.

2. Narciso V, Henriques P. Women and land in Timor-Leste: issues in gender and development. Indian Journal of Gender Studies. 2010;17(1):49-72.

3. Summary report on gender based violence study in Covalima and Oecusse. Oxfam; 2012 Jun.

4. Robertson K. Gender-based violence in Timor-Leste: a case study. Bucharest, Romania: UNFPA Women, Peace and Security Technical Support Division; 2005 Oct.

5. Alves MDF, Sequeira IMM, Abrantes LS, Reis F. Baseline study on sexual and genderbased violence in Bobonaro and Covalima. Dili, Timor-Leste: Asia Pacific Support Collective Timor-Leste; 2009. Supported by UNIFEM and funded by DFID-UK.

6. de Sousa R. Women of Timor-Leste: seeking freedom in a free nation. Development Bulletin. 2005 Oct;68:34-5.

7. Harris-Rimmer S. After the guns fall silent: sexual and gender-based violence in Timor-Leste. Issue brief. Timor-Leste Armed Violence Assessment (TLAVA); 2009 Nov. Issue Brief No.: 5.

8. Underlying causes of gender inequity in Covalima, Timor-Leste. Final report. Oxfam Australia; 2003 Sept. Funded by NZAID, Government of New Zealand.

9. Niner S. Hakat Klot, Narrow Steps. International Feminist Journal of Politics. 2011;13(3)413-435. 
10. Silove D, Liddell B, Rees S, Chey T, Nickerson A, Tam N, Zwi AB, Brooks R, Sila LL, Steel Z. Effects of recurrent violence on post-traumatic stress disorder and severe distress in conflict-affected Timor-Leste: a 6-year longitudinal study. Lancet Glob Health. 2014;2(5);e293-300.

11. Silove D, Brooks R, Bateman Steel CR, Steel Z, Hewage K, Rodger J, Soosay I. Explosive anger as a response to human rights violations in post-conflict TimorLeste. Soc Sci Med. 2009;69(5):670-7.

12. Chega! The report of the Commission for Reception, Truth, and Reconciliation. Timor-Leste: Commission for Reception, Truth, and Reconciliation Timor-Leste (CAVR); 2005.

13. Hall N. East Timorese women challenge domestic violence. Aust J Polit Sci. 2009;44(2):309-325.

14. National Statistics Directorate (NSD) [Timor-Leste], Ministry of Finance [TimorLeste], ICF Macro. Timor-Leste Demographic and Health Survey 2009-10. Dili, Timor-Leste: NSD [Timor-Leste] and ICF Macro; 2010. Available from: http://dhsprogram.com/pubs/pdf/FR235/FR235.pdf

15. Sarkar NN. The impact of intimate partner violence on women's reproductive health and pregnancy outcome. J Obstet Gynaecol. 2008;28(3):266-71.

16. Mezey GC, Bewley S. Domestic violence and pregnancy. BJOG. 1997;104:528-31.

17. Pallitto CC, Garcia-Moreno C, Jansen HAFM, Heise L, Ellsberg M, Watts C, on behalf of the WHO Multi-Country Study on Women's Health and Domestic Violence. Intimate partner violence, abortion, and unintended pregnancy: results from the WHO multi- 
country study on women's health and domestic violence. Int J Gynaecol Obstet. 2013;120(1):3-9.

18. Cook J, Bewley S. Acknowledging a persistent truth: domestic violence in pregnancy. J R Soc Med. 2008;101:358-63.

19. Alio AP, Nana PN, Salihu HM. Spousal violence and potentially preventable single and recurrent spontaneous fetal loss in an African setting: cross-sectional study. Lancet. 2009;373(9660):318-24.

20. Bailey BA. Partner violence during pregnancy: prevalence, effects, screening, and management. International Journal of Women's Health. 2010;2:183-97.

21. Stephenson R, Koenig MA, Acharya R, Roy TK. Domestic violence, contraceptive use, and unwanted pregnancy in rural India. Stud Fam Plann. 2008;39(3):177-86.

22. Williams CM, Larsen U, McCloskey LA. Intimate partner violence and women's contraceptive use. Violence Against Women. 2008;14(12):1382-96.

23. Taft A, Watson L. Violence against women in Timor-Leste - secondary analysis of the 2009-10 Demographic Health Survey. Final report. Mother and Child Health Research, La Trobe University; 2013 Jul. Funded by AusAID through the Timor-Leste Justice Sector Support Facility.

24. Deen J, Matos LdC, Temple B, Su JY, da Silva J, Liberato S, da Silva V, Soares AI, Joshi V, Moon S, Tulloch J, Martins J, Mulholland K. Identifying national health research priorities in Timor-Leste through a scoping review of existing health data. Health Res Policy Syst. 2013;11(8).

25. World Health Organization, Department of Making Pregnancy Safer and Department of Reproductive Health and Research. Provision of effective antenatal care. In: 
Standards for Maternal and Neonatal Care. World Health Organization; 2007. Available from:

http://www.who.int/reproductivehealth/publications/maternal_perinatal_health/a 91272/en/

26. Devries KM, Kishor S, Johnson H, Stockl H, Bacchus LJ, Garcia-Moreno C, Watts C. Intimate partner violence during pregnancy: analysis of prevalence data from 19 countries. Reprod Health Matters. 2010;18(36):158-70.

27. World Health Organization/London School of Hygiene and Tropical Medicine.

Preventing intimate partner and sexual violence against women: taking action and generating evidence. Geneva: World Health Organization; 2010. 
Table 1. Samples used and outcomes tested

\begin{tabular}{|c|c|c|}
\hline Sample & Description & Outcomes Tested \\
\hline $\begin{array}{l}\text { Sample } 1 \\
(\mathrm{~N}=2,162)\end{array}$ & $\begin{array}{l}\text { - Participated in DV module } \\
\text { - Ever-married women }\end{array}$ & Unmet need for family planning \\
\hline $\begin{array}{l}\text { Sample } 2 \\
(\mathrm{~N}=570)\end{array}$ & $\begin{array}{l}\text { - } \text { Participated in DV module } \\
\text { - Ever-married women } \\
\text { - } \text { Either gave birth in the past six } \\
\text { months or were currently pregnant }\end{array}$ & Unplanned pregnancy \\
\hline $\begin{array}{l}\text { Sample } 3 \\
(\mathrm{~N}=294)\end{array}$ & $\begin{array}{l}\text { - Participated in DV module } \\
\text { - Ever-married women } \\
\text { - Gave birth in past six months }\end{array}$ & $\begin{array}{l}\text { For most recent birth: } \\
\text { - } \text { No antenatal care from a } \\
\text { skilled antenatal care } \\
\text { provider } \\
\text { - } \text { Fewer than four } \\
\text { antenatal care visits } \\
\text { - } \text { Did not use a skilled } \\
\text { birth attendant } \\
\text { - } \text { Delivered outside of a } \\
\text { healthcare facility } \\
\text { - } \text { Mother reports baby was } \\
\text { small or very small at } \\
\text { birth } \\
\text { - No maternal postnatal } \\
\text { check within one day } \\
\text { after birth } \\
\text { - No maternal postnatal } \\
\text { check within six weeks } \\
\text { after birth }\end{array}$ \\
\hline
\end{tabular}


Table 2. Background characteristics of women in each sample

\begin{tabular}{|c|c|c|c|}
\hline & \multicolumn{2}{|c|}{ Family planning outcomes } & \multirow[b]{2}{*}{$\begin{array}{l}\text { Maternal healthcare and birth outcomes } \\
\text { Sample 3: Ever-married women who have given birth in } \\
\text { the past six months and participated in the DV module } \\
\text { Outcomes tested: } \\
\text { 1. No antenatal care from a skilled antenatal care } \\
\text { provider } \\
\text { 2. Fewer than four antenatal care visits } \\
\text { 3. Did not use a skilled birth attendant } \\
\text { 4. Delivered outside of a healthcare facility } \\
\text { 5. Mother reported baby was small or very small at } \\
\text { birth } \\
\text { 6. No maternal postnatal check within one day after } \\
\text { b. No maternal postnatal check within six weeks } \\
\text { after birth }\end{array}$} \\
\hline & $\begin{array}{l}\text { Sample 1: Ever- } \\
\text { married women } \\
\text { who participated in } \\
\text { the DV module } \\
\text { Outcome tested: } \\
\text { Unmet need for } \\
\text { family planning }\end{array}$ & $\begin{array}{l}\text { Sample 2: Ever- } \\
\text { married womenn } \\
\text { who have given } \\
\text { birth in the past six } \\
\text { months or were } \\
\text { currently pregnant } \\
\text { who participated in } \\
\text { the DV module } \\
\text { Outcome tested: } \\
\text { Unplanned } \\
\text { pregnancy }\end{array}$ & \\
\hline$N$ & 2,162 & 570 & 294 \\
\hline $\begin{array}{l}\text { Wealth Tertile } \\
\text { Poorest } \\
\text { Middle } \\
\text { Richest } \\
\end{array}$ & $\begin{array}{l}36.7 \% \\
32.5 \% \\
30.9 \% \\
\end{array}$ & $\begin{array}{l}39.5 \% \\
33.9 \% \\
26.7 \% \\
\end{array}$ & $\begin{array}{l}42.9 \% \\
31.3 \% \\
25.9 \% \\
\end{array}$ \\
\hline $\begin{array}{l}\text { Education Level } \\
\text { No education } \\
\text { Primary } \\
\text { Secondary and higher }\end{array}$ & $\begin{array}{l}37.0 \% \\
27.6 \% \\
35.4 \% \\
\end{array}$ & $\begin{array}{l}33.3 \% \\
27.9 \% \\
38.8 \% \\
\end{array}$ & $\begin{array}{l}35.0 \% \\
29.6 \% \\
35.4 \% \\
\end{array}$ \\
\hline $\begin{array}{l}\text { Residence } \\
\text { Urban } \\
\text { Rural }\end{array}$ & $\begin{array}{l}23.2 \% \\
76.8 \% \\
\end{array}$ & $\begin{array}{l}25.1 \% \\
74.9 \% \\
\end{array}$ & $\begin{array}{l}25.9 \% \\
74.1 \% \\
\end{array}$ \\
\hline $\begin{array}{l}\text { Age } \\
\text { Average age in years }\end{array}$ & 33.1 & 28.9 & 29.4 \\
\hline $\begin{array}{l}\text { Marital Status } \\
\text { Currently married } \\
\text { Formerly married }\end{array}$ & $\begin{array}{c}95.1 \% \\
4.9 \%\end{array}$ & $\begin{array}{c}98.6 \% \\
1.4 \% \\
\end{array}$ & $\begin{array}{l}97.6 \% \\
2.4 \% \\
\end{array}$ \\
\hline $\begin{array}{l}\text { Report physical or } \\
\text { sexual violence from } \\
\text { partner } \\
\text { No } \\
\text { Yes }\end{array}$ & $\begin{array}{l}64.6 \% \\
35.4 \%\end{array}$ & $\begin{array}{l}60.5 \% \\
39.5 \%\end{array}$ & $\begin{array}{l}59.5 \% \\
40.5 \%\end{array}$ \\
\hline $\begin{array}{l}\text { Report that partner } \\
\text { displays } 3 \text { or more } \\
\text { controlling behaviors } \\
\text { No } \\
\text { Yes }\end{array}$ & $\begin{array}{l}88.7 \% \\
11.3 \%\end{array}$ & $\begin{array}{l}87.2 \% \\
12.8 \%\end{array}$ & $\begin{array}{l}87.4 \% \\
12.6 \%\end{array}$ \\
\hline
\end{tabular}


Table 3. Odds of negative family planning outcomes for ever-married women who report experiencing domestic violence ${ }^{a}$ compared to those who do not, and for women who report experiencing marital control and those who do not, by residence (unadjusted and adjusted ${ }^{b}$ odds ratios)

\begin{tabular}{|c|c|c|}
\hline Outcome frequency & $\begin{array}{c}\text { Relative odds of } \\
\text { having an unmet } \\
\text { need for family } \\
\text { planning } \\
28.9 \%\end{array}$ & $\begin{array}{c}\text { Relative odds of } \\
\text { having an } \\
\text { unplanned } \\
\text { pregnancy } \\
16.8 \%\end{array}$ \\
\hline $\begin{array}{l}\text { Women who report } \\
\text { experiencing domestic } \\
\text { violence compared to } \\
\text { those who do not }\end{array}$ & & \\
\hline $\begin{array}{l}\text { Overall } \\
\text { Unadj. OR }(95 \% \mathrm{Cl}) \\
\text { AdjOR }(95 \% \mathrm{Cl})\end{array}$ & $\begin{array}{r}N=2162 \\
0.8(0.6,1.0) \\
0.8(0.6,1.0)\end{array}$ & $\begin{array}{r}N=570 \\
\mathbf{2 . 3}^{\star \star}(1.3,3.9) \\
\mathbf{2 . 2}^{\star \star}(1.3,3.7)\end{array}$ \\
\hline $\begin{array}{l}\text { Urban } \\
\text { Unadj. OR }(95 \% \mathrm{Cl}) \\
\text { AdjOR }(95 \% \mathrm{Cl})\end{array}$ & $\begin{array}{r}N=501 \\
0.7(0.4,1.2) \\
0.7(0.4,1.2)\end{array}$ & $\begin{array}{r}N=143 \\
1.3(0.5,3.4) \\
1.5(0.5,4.1)\end{array}$ \\
\hline $\begin{array}{l}\text { Rural } \\
\text { Unadj. OR }(95 \% \mathrm{Cl}) \\
\text { AdjOR }(95 \% \mathrm{Cl})\end{array}$ & $\begin{array}{r}N=1661 \\
0.8(0.6,1.1) \\
0.8(0.6,1.1)\end{array}$ & $\begin{array}{r}N=427 \\
\mathbf{2 . 8}^{\star \star}(1.5,5.2) \\
\mathbf{2 . 6}^{\star \star}(1.4,4.8)\end{array}$ \\
\hline $\begin{array}{l}\text { Women who report } \\
\text { experiencing marital } \\
\text { control compared to } \\
\text { those who do not }\end{array}$ & & \\
\hline $\begin{array}{r}\text { OR }(95 \% \mathrm{Cl}) \\
\text { AdjOR }(95 \% \mathrm{Cl})\end{array}$ & $\begin{array}{r}N=2162 \\
0.8(0.6,1.1) \\
0.8(0.6,1.1)\end{array}$ & $\begin{array}{r}N=570 \\
2.1^{*}(1.0,4.3) \\
2.2^{*}(1.0,4.5)\end{array}$ \\
\hline $\begin{array}{r}\text { OR }(95 \% \mathrm{Cl}) \\
\text { AdjOR }(95 \% \mathrm{Cl})\end{array}$ & $\begin{array}{r}N=501 \\
1.3(0.8,2.2) \\
1.4(0.8,2.4)\end{array}$ & $\begin{array}{r}N=143 \\
1.8(0.6,5.6) \\
1.9(0.6,5.9)\end{array}$ \\
\hline $\begin{array}{r}\text { OR }(95 \% \mathrm{Cl}) \\
\text { AdjOR }(95 \% \mathrm{Cl})\end{array}$ & 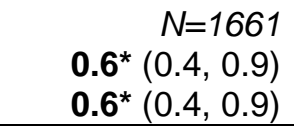 & $\begin{array}{r}N=427 \\
2.0(0.8,5.3) \\
2.0(0.8,5.3)\end{array}$ \\
\hline
\end{tabular}

OR, Odds Ratio; AdjOR, Adjusted Odds Ratio; Cl, confidence interval.

a Physical or sexual violence from current or most recent partner

${ }^{b}$ Adjusted for age, education level, and wealth

${ }^{*} p<0.05 \quad{ }^{* *} p<0.01 \quad{ }^{* * *} p<0.001$ 
Table 4. Odds of negative maternal healthcare and birth outcomes for ever-married women who report experiencing domestic violence ${ }^{\mathrm{a}}$ compared to those who do not, by residence (unadjusted and adjusted ${ }^{\mathrm{b}}$ odds ratios)

\begin{tabular}{|c|c|c|c|c|c|c|c|}
\hline Outcome frequency & $\begin{array}{l}\text { Relative odds of } \\
\text { having no } \\
\text { antenatal care } \\
\text { from a skilled } \\
\text { antenatal care } \\
\text { providerc } \\
16.3 \% \\
\end{array}$ & $\begin{array}{l}\text { Relative odds of } \\
\text { having fewer than } \\
\text { four antenatal } \\
\text { care visits } \\
48.5 \%\end{array}$ & $\begin{array}{l}\text { Relative odds of } \\
\text { not using a } \\
\text { skilled birth } \\
\text { attendant } \\
\\
65.6 \% \\
\end{array}$ & $\begin{array}{l}\text { Relative odds of } \\
\text { delivery outside of } \\
\text { healthcare facility }\end{array}$ & $\begin{array}{c}\text { Relative odds of } \\
\text { mother reporting } \\
\text { baby was small or } \\
\text { very small at birth } \\
20.0 \% \\
\end{array}$ & $\begin{array}{l}\text { Relative odds of } \\
\text { having no } \\
\text { maternal } \\
\text { postnatal check } \\
\text { within one day } \\
\text { after birth } \\
75.8 \% \\
\end{array}$ & $\begin{array}{c}\text { Relative odds of } \\
\text { having no } \\
\text { maternal } \\
\text { postnatal check } \\
\text { within six weeks } \\
\text { after birth } \\
63.5 \% \\
\end{array}$ \\
\hline $\begin{array}{r}\text { Overall } \\
\text { Unadj. OR }(95 \% \mathrm{Cl}) \\
\text { AdjOR }(95 \% \mathrm{Cl})\end{array}$ & $\begin{array}{r}N=294 \\
1.4(0.7,2.8) \\
1.9(0.9,3.9)\end{array}$ & $\begin{array}{r}N=291 \\
\mathbf{2 . 2}^{\star}(1.2,3.9) \\
\mathbf{2 . 7}^{\star \star}(1.4,5.1)\end{array}$ & $\begin{array}{r}N=294 \\
0.7(0.4,1.3) \\
0.9(0.5,1.8)\end{array}$ & $\begin{array}{r}N=294 \\
0.7(0.4,1.3) \\
0.9(0.4,1.9)\end{array}$ & $\begin{array}{r}N=290 \\
1.8(0.9,3.7) \\
2.1(1.0,4.4)\end{array}$ & $\begin{array}{r}N=293 \\
0.5(0.3,1.0) \\
0.6(0.3,1.3)\end{array}$ & $\begin{array}{r}N=293 \\
0.7(0.4,1.3) \\
0.8(0.4,1.6)\end{array}$ \\
\hline $\begin{array}{r}\text { Urban } \\
\text { Unadj. OR (95\% Cl) } \\
\text { AdjOR }(95 \% \mathrm{Cl})\end{array}$ & $\begin{array}{r}N=76 \\
6.7(0.6,71.8) \\
9.1(0.7,125.2)\end{array}$ & $\begin{array}{r}N=74 \\
2.6(0.8,8.6) \\
3.4(0.8,13.6)\end{array}$ & $\begin{array}{r}N=76 \\
0.5(0.2,1.4) \\
0.6(0.2,1.8)\end{array}$ & $\begin{array}{r}N=76 \\
1.0(0.3,2.7) \\
1.2(0.3,4.5)\end{array}$ & $\begin{array}{r}N=75 \\
0.5(0.1,2.5) \\
0.5(0.1,3.4)\end{array}$ & $\begin{array}{r}N=76 \\
0.9(0.3,2.7) \\
1.0(0.3,3.7)\end{array}$ & $\begin{array}{r}N=76 \\
0.7(0.2,2.3) \\
0.8(0.2,3.0)\end{array}$ \\
\hline $\begin{array}{r}\text { Rural } \\
\text { Unadj. OR }(95 \% \mathrm{Cl}) \\
\text { AdjOR }(95 \% \mathrm{Cl})\end{array}$ & $\begin{array}{r}N=218 \\
1.4(0.6,3.2) \\
1.3(0.6,3.0)\end{array}$ & $\begin{array}{r}N=217 \\
\mathbf{2 . 2}^{*}(1.1,4.4) \\
\mathbf{2 . 3}^{\star}(1.1,4.9)\end{array}$ & $\begin{array}{r}N=218 \\
1.1(0.5,2.4) \\
1.1(0.5,2.7)\end{array}$ & $\begin{array}{r}N=218 \\
0.9(0.4,2.1) \\
0.9(0.4,2.3)\end{array}$ & $\begin{array}{r}N=215 \\
\mathbf{2 . 8}^{\star}(1.3,6.2) \\
\mathbf{3 . 1}^{* \star}(1.4,6.7)\end{array}$ & $\begin{array}{r}N=217 \\
0.5(0.2,1.2) \\
0.5(0.2,1.2)\end{array}$ & $\begin{array}{r}N=217 \\
0.9(0.4,2.0) \\
0.9(0.4,2.0)\end{array}$ \\
\hline
\end{tabular}

OR, Odds Ratio; AdjOR, Adjusted Odds Ratio; Cl, confidence interval

a Physical or sexual violence from current or most recent partner

b Adjusted for age, education level, and wealth

c Due to small sample size, the model that tested odds of having no antenatal care from a skilled antenatal care provider did not control for wealth.

${ }^{*} p<0.0{ }^{* *} p<0.01 \quad{ }^{* * *} p<0.001$ 


\section{Acknowledgements}

Many, many thanks to Judy Meiksin and Ben Pelhan for their support and feedback throughout this project. 


\section{Endnotes}

$i$ "Ever-married women" refers to women who have ever been married or lived with a man as if married. "Partner" refers to a man a respondent has married and to any man a respondent has lived with as if married.

ii Injuries include cuts, bruises, aches, eye injuries, sprains, dislocations, burns, deep wounds, broken bones, broken teeth, or any other serious injury.

iii Of the six controlling behaviors asked about in the TLDHS

iv This is not a possibility for the outcome of unmet need for family planning, which is measured at the time of the survey.

$\checkmark$ "Skilled ANC provider" includes doctor, nurse, midwife, or assistant nurse

vi "Skilled birth attendant" includes doctor, nurse, midwife, or assistant nurse

vii Because birthweight was reported for only $26 \%$ of births in the five years preceding the survey, we instead use mother's estimate of the baby's size at birth in our analysis. This estimate is considered a good proxy for birthweight when recorded birthweight is not available.(14,p.131)

viii To illustrate with an example, we tested whether DV could be a confounder in the relationship between marital control and unmet need for family planning by running Chi-square tests to determine if DV was significantly associated with marital control and with unmet need for family planning within the relevant sample.

ix Due to small sample size, the model that tested receiving no care from a skilled ANC provider did not control for wealth. 